\title{
Designing a test rig for structural static-load testing of small horizontal axis wind turbine rotor blades
}

\author{
Tran Trung Tien, Pham Quoc Hung, Ngo Khanh Hieu*
}

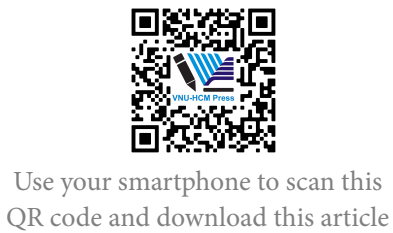

VNU-HCM Key Laboratory for Internal Combustion Engine

\section{Correspondence}

Ngo Khanh Hieu, VNU-HCM Key Laboratory for Internal Combustion Engine

Email: ngokhanhhieu@hcmut.edu.v

History

- Received: 01-5-2020

- Accepted: 30-12-2020

- Published: 15-1-2021

DOI : 10.32508/stdjet.v3iSI3.739

\section{Check for updates}

\section{Copyright}

(c) VNU-HCM Press. This is an openaccess article distributed under the terms of the Creative Commons Attribution 4.0 International license.

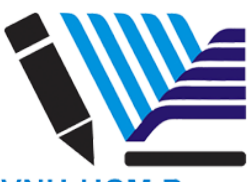

VNU-HCM Press

\section{ABSTRACT}

This paper presents a design of a test rig for structural static load testing of small horizontal wind turbine blades. It is a next step after the success of the DeVie project, a join-research project to boost the wind energy knowhow between Germany and Vietnam. According to the IEC-61400-23 standard for full scale structural testing of rotor blades, and based on existing facilities of HCMUT, especially the aerospace engineering lab. and the engineering mechanics lab., we propose a prototype of a test-rig for structural static load testing of rotor blades. A rotor blade of 4 meters in length, manufactured by China, is used in the case study of our structural static-load test-rig. This paper used the reverse engineering method to determine the bladegeometry and performance, since the blade was provided and not designed from scratch. Detar s eps to determine the test load for the rig are the most important, based on the blade desion and the wind condition of Vietnam, a study case was set to start the process. Since that re quil da lot of experience and know-how, beside the work and research from our university ot aiti ally important information was kindly provided by the German's experts in the field. Res t of he blade tip displacement are wildly used in this industry to validate the blade design. Qu res rig result in 0.289 meters were compared to the reverse engineering and simulation result of 0.28 meter with QBlade/FAST in the same blade loading shown well similarity, this result yalida our work process. Future revision of the test rig is promised to provide more function such s stigue test mode, higher load capacity, faster testing time as well as more accurate result aidin he domestic market of composite wind turbine blade manufacturing which is still in its.inf ncy.

Key words: Static load test Stmirtury rotor blades test rig, IEC 61400-23 standard, QBlade/FAST INTRODUCTION ter renewable en rgy har vesting solutions. Have been widely knoy a its huge wind energy potential, but it con $w$ th challenging characteristics of low velocity na ing it less attractive to big European wind tu o1. wrich has always been design for high wind sp But on the other hand, ignoring the huge markensegment for low velocity wind turbine, which is the research and manufacturing potential for the developing and inexperienced wind energy industry in Vietnam. Figure 1 shows the average wind speed at the hub height of 40 meters in several region of Vietnam, data provided by GIZ ${ }^{1,2}$.

The DeVie wind turbine project is a German-Vietnam Research Cooperation on Wind Power Initiative ${ }^{3}$. Figure 2 shows the preliminary design concept of DeVie horizontal axis wind turbine (HAWT) of $100 \mathrm{~kW}$ according to IEC $61400-1$ standard $^{4}$, suitable for the wind condition in Vietnam. Figure 3 shows a prototype of a down-scale DeVie blade which had been successfully built by a group of HCMUT student as the exchange knowledge program, with the guidance of an expert in the manufacturing department from Fraunhofer IWES $^{3}$, using vacuum infusion as the manufacturing process.

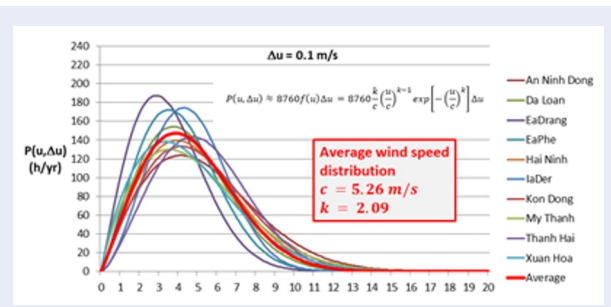

Figure 1: Wind speed at hub height of $40 \mathrm{~m}$

In an effort to continue the success of the DeVie wind turbine project, a novel research proposed a test rig for structural static-load testing of small horizontal axis wind turbine rotor blades is funded by $\mathrm{HCMUT}^{5}$. In this project, with reference to the rotor blades testing system of Fraunhofer IWES Institute ${ }^{3}$, a design concept of the test rig was made, with some limitation of manufacture ability caused by the existing facilities 

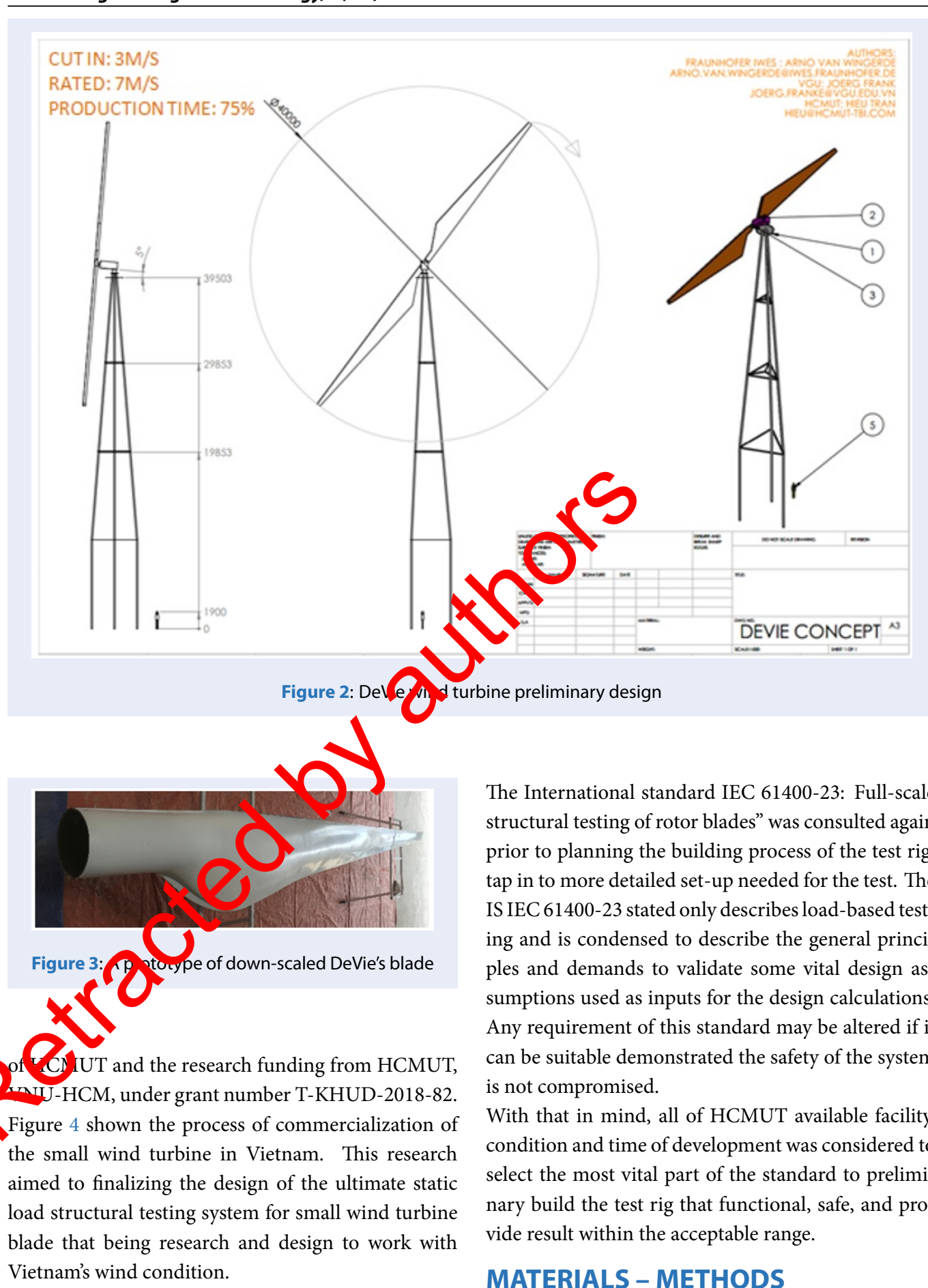

The International standard IEC 61400-23: Full-scale structural testing of rotor blades" was consulted again prior to planning the building process of the test rig, tap in to more detailed set-up needed for the test. The IS IEC 61400-23 stated only describes load-based testing and is condensed to describe the general principles and demands to validate some vital design assumptions used as inputs for the design calculations. Any requirement of this standard may be altered if it can be suitable demonstrated the safety of the system is not compromised.

With that in mind, all of HCMUT available facility, condition and time of development was considered to select the most vital part of the standard to preliminary build the test rig that functional, safe, and provide result within the acceptable range.

\section{MATERIALS - METHODS}

\section{Testing Standard}

This test rig design mainly came from the exchanged knowhow from the German expert and from real experience of the student who taken 3 months internship working on various department (blade testing, manufacturing, sub-component testing) in Fraunhofer Institute for Wind Energy and Energy System Technology in Germany.

\section{ANALYSIS OF THE HORIZONTAL AXIS WIND TURBINE ROTOR BLADE}

The main focus of this paper is the mechanical parts, testing procedure, and real test result. Thus, this part of the paper explaining theoretical evaluation was taken from the QBlade analysis tool transferring results in the GIZ project, and report from National mechanical conference ${ }^{11}$. 


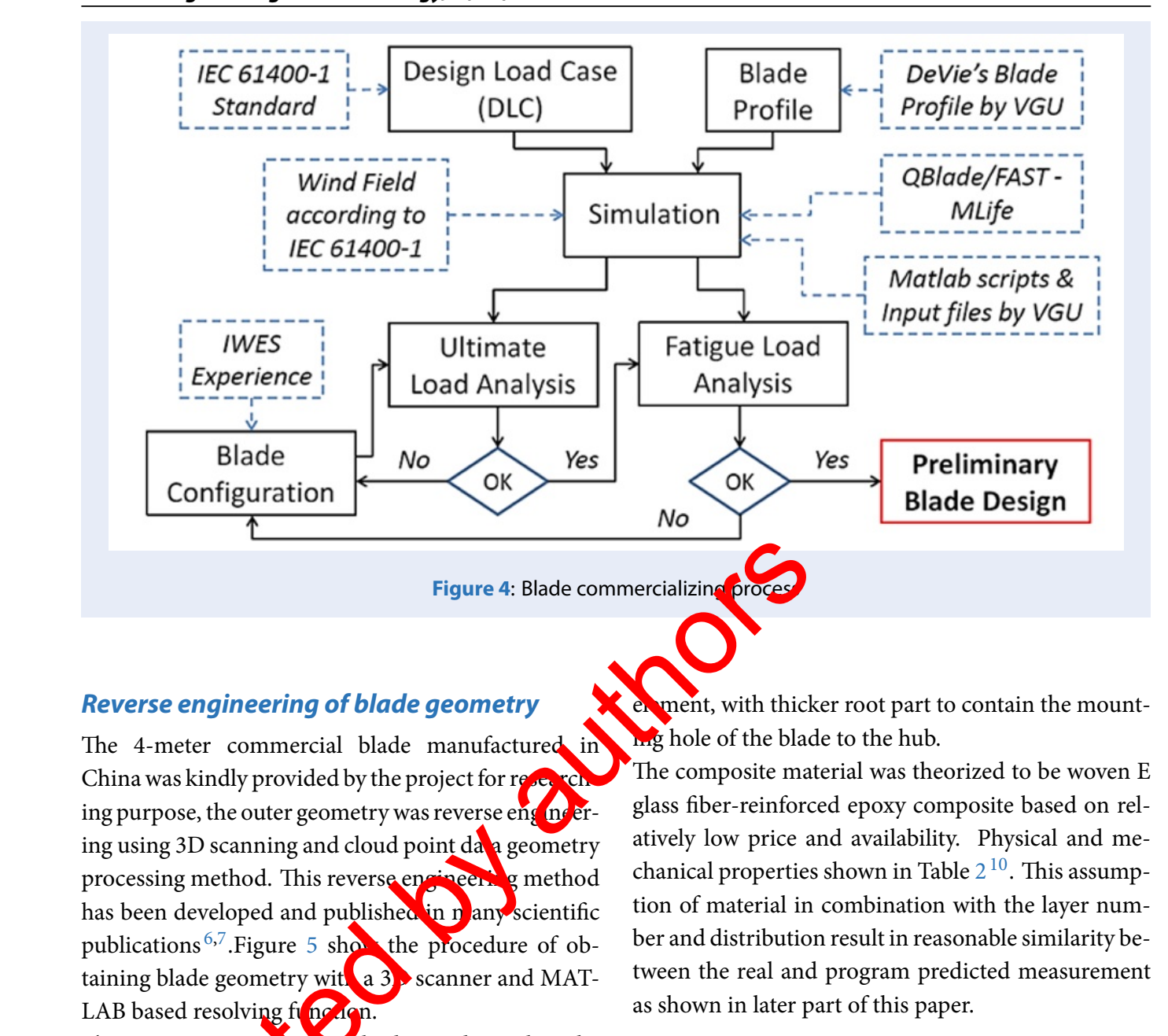

This reverse enginee ing hothod provide result in the outer blade's ge mety structure. Figure 6 show the 15 represen at anroil sections, chosen for remodeling pre ess. T. ble 1 show the detailed profile type at variab cross section.

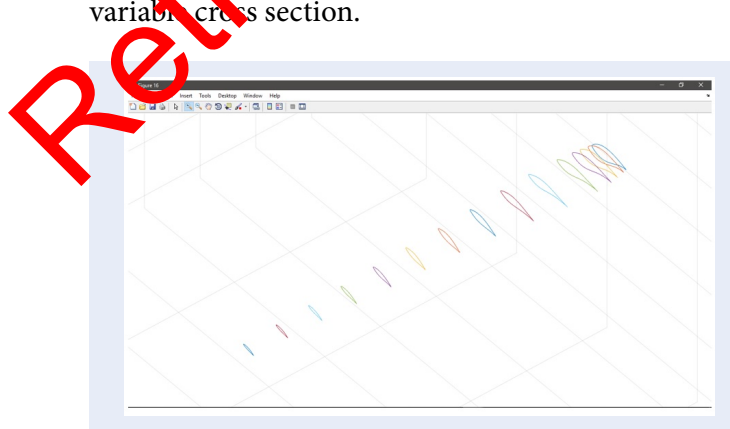

Figure 6: Blade's geometry rebuilt in MATLAB

Since the provided blade detail for inner structure was not available from the manufacturer, an educated assumption was made from the blade size, weight and price. Since this blade was commercialized, the size, weight and price point suggest it contain of the shell

\section{Power properties evaluation theory}

The DeVie wind turbine project reported the average wind speed of Vietnam are from $5.5 \mathrm{~m} / \mathrm{s}$ to 6.5 $\mathrm{m} / \mathrm{s}$. The designed parameter of the small wind turbine with the rotor diameter of 8 meters are show in Table 3. There is a noticeable difference between the design wind speed of $9 \mathrm{~m} / \mathrm{s}$ compared to the average wind speed spectrum of Vietnam. Hence a power characteristics analysis has been carried out in order to re-evaluate the actual power capacity of the wind turbine as it deployed in Vietnam.

Referred to the power evaluating process using momentum wing elements theory ${ }^{3}$, with 3 typical wing sections at the position of $0.2 \mathrm{R}, 0.5 \mathrm{R}, 1 \mathrm{R}$. Figure 7 shown the position and aerodynamic characteristics of the three typical wing sections generated with XFOIL at the Reynolds number of $2.55 \times 10^{5}$. The data shown the maximum of lift-to-drag ratio $\left(\max \mathrm{C}_{l} / \mathrm{C}_{d}\right)$ of the small horizontal axis wind turbine with the rotor diameter of 8 meters is 70 at the tip of the blade. From the lift-to-drag ratio indicated in the above statement, apply to the Certin equation ${ }^{8}$, the Tip 


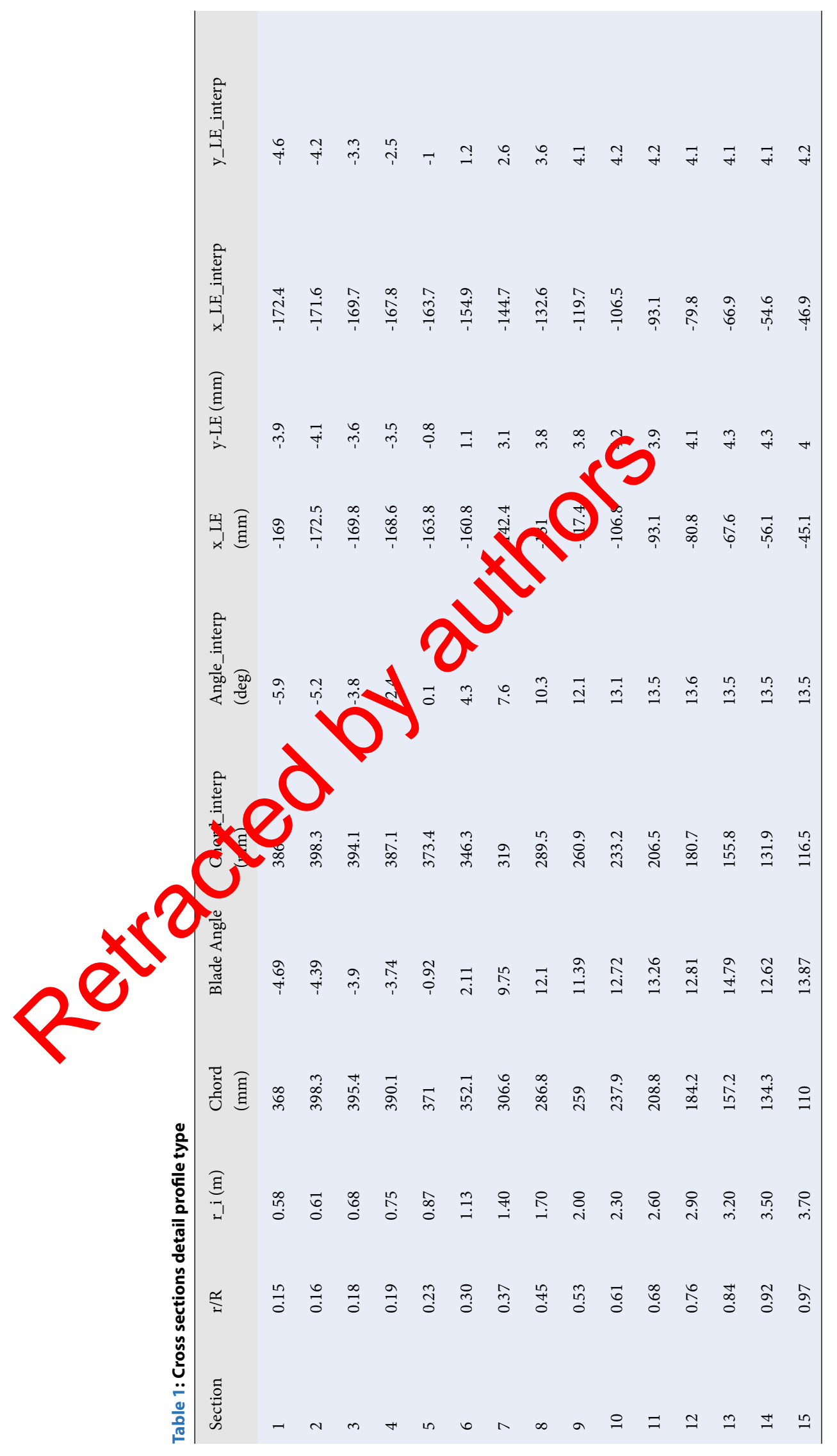




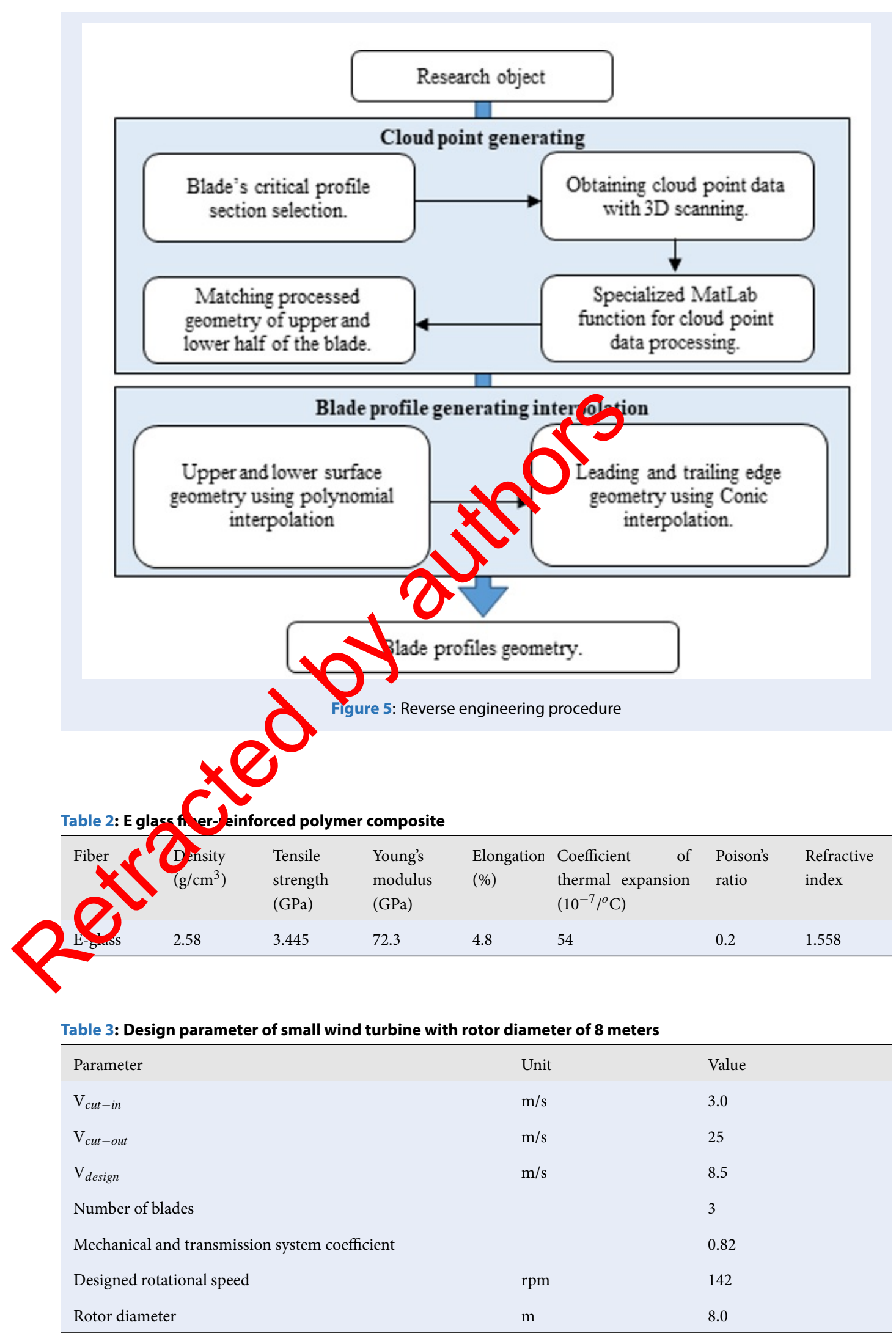


Speed Ratio (TSR) of the horizontal axis wind turbine can be selected at 7 for maximum power conversion efficiency.

Figure 8 shown the respectively twisting angle of the blade to the blade's sections position. The analysis result shares the same similarity with the measurement result show the blade has been designed base on the Blade Element Momentum theory (BEM).

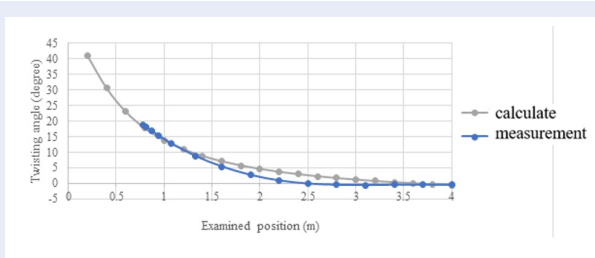

Figure 8: Respective twisting angle to blade sections

Further referred to the BEM theory, with the Tip los factor determined by the Prandtl's lifting-line theor result in the power factor of the blade is 0.46 . With he fixed twist angle design and variable rotation 1 sp
of the wind turbine, as the wind speed are und the of the wind turbine, as the wind speed are und the
designed speed, the tip speed ratio ill emain the same and vice versa at 0 .

Figure 9 shown the powe outpu ferred to the Weibull distribution of win isped of Vietnam could be theoretically achieve $15 \mathrm{MWh} /$ year.

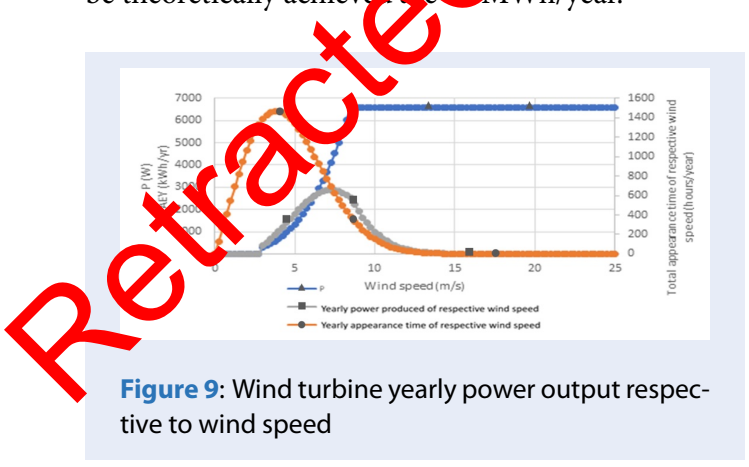

\section{Power properties evaluation with QBlade/FAST}

First step is to modeling the blade geometry on QBlade/FAST required the parameter acquired from the reverse engineering airfoil, with the twisting angle according to the BEM theory, this will result in the blade model shown inFigure 10 .

Next step is to establish a data set of extrapolated 360 degrees according to the Montgomerie method ${ }^{9}$ using the blade model obtained in the first step. So, along with the options provided on QBlade/FAST on the tip loss ratio, Himmelskamp effect and drag to Reynolds variation, in which the BEM theory is not achievable, are also used in this step.

The third step is to setup the control model of the blade on the horizontal axis wind turbine. In this case, if the ynd speed is lower than the design wind speed, th rotati nal speed can be adjusted to match the man mower TSR. If the wind speed is above the a sig ed wind speed, the rotational speed would e fixd at 142 round/minute (RPM). Figure 11 shows theresults of BEM theory analysis of QBlade/FAST in form of yearly power output about 16.6 MWh/year if ignore the mechanical loss, and 13.6 MWh/year vice versa.

QBlade/FAST provide user with the wind field generator for the power characteristics simulate of the wind condition given in the DLC 1.1 of IEC 614001 . With the respective setting of mean wind speed at $8.5 \mathrm{~m} / \mathrm{s}$, hub height of 20 meters, turbulence intensity of $22.54 \%$, roughness length of 0.3 meters, rotor radius of 4 meters, Figure 12 shown the generated wind field with all the setting mentioned above.

Figure 13 presents the performance characteristics of this rotor blade with QLLT simulation in 300 seconds, and the wind field generated by Wind field generator of QBlade (see Fig. 11). They are the power properties, the out-of-plane bending moment...

The rotor blade's power output at wind speed of 8.5 $\mathrm{m} / \mathrm{s}$ obtained from the simulation is about $6.7 \mathrm{~kW}$, which is lower than the power output of $10 \mathrm{~kW}$ announced by manufacturer.

In order to make static analysis of the rotor blade structure, QBlade/FAST provides the tools for modeling the blade mechanical properties via its material. A survey is shown that a rotor blade made of glass fiber woven mat composite material has the tensile modulus of $18 \mathrm{GPa}^{10}$. Figure 14 shows the preliminary configuration setting suitable for the rotor blade. The estimated weight of one blade from QBlade is $36.9 \mathrm{~kg}$ (in comparison with the actual weight of $37 \mathrm{~kg} / \mathrm{blade}$ ). After feeding QBlade/FAST with the material properties of rotor blade, the static durability of the blade can 


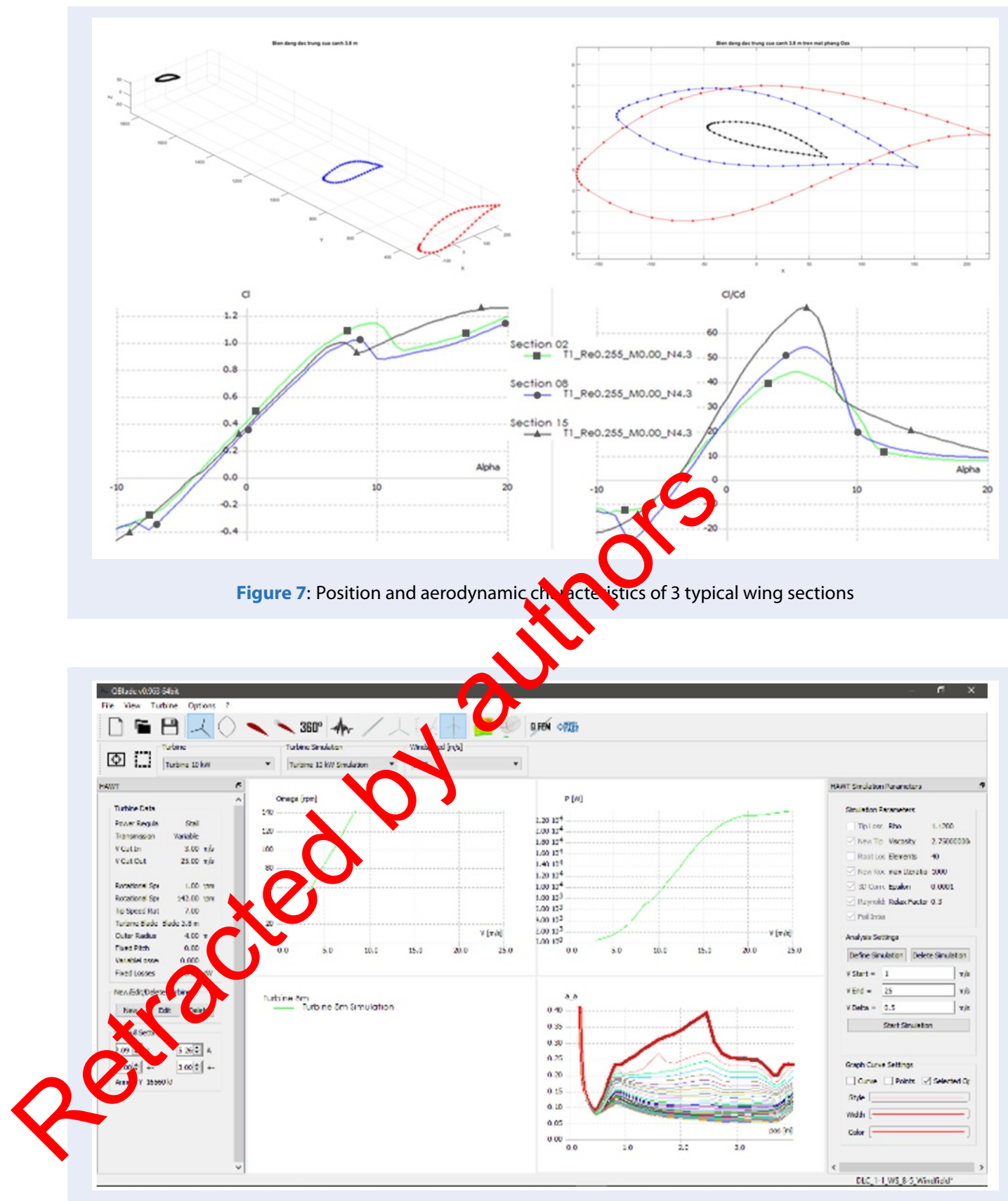

Figure 11: Blade's power output analysis of BEM theory of QBlade/FAST

now be simulated. The maximum bending moment and displacement of the blade are calculated based on the DLC 6.1 of IEC 61400-1, representing the parked wind turbine with extreme wind speed model. Figure 15 shown the bending moment at the respective blade length and Figure 16 shown the tip displacement in time, taken from this figure the simulated maximum blade's tip displacement of 0.28 meters.
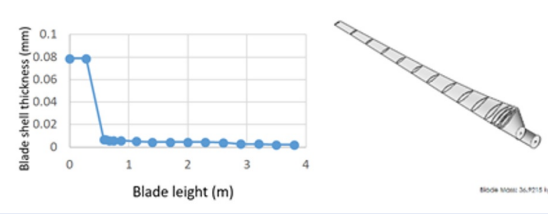

Figure 14: Blade preliminary configuration 


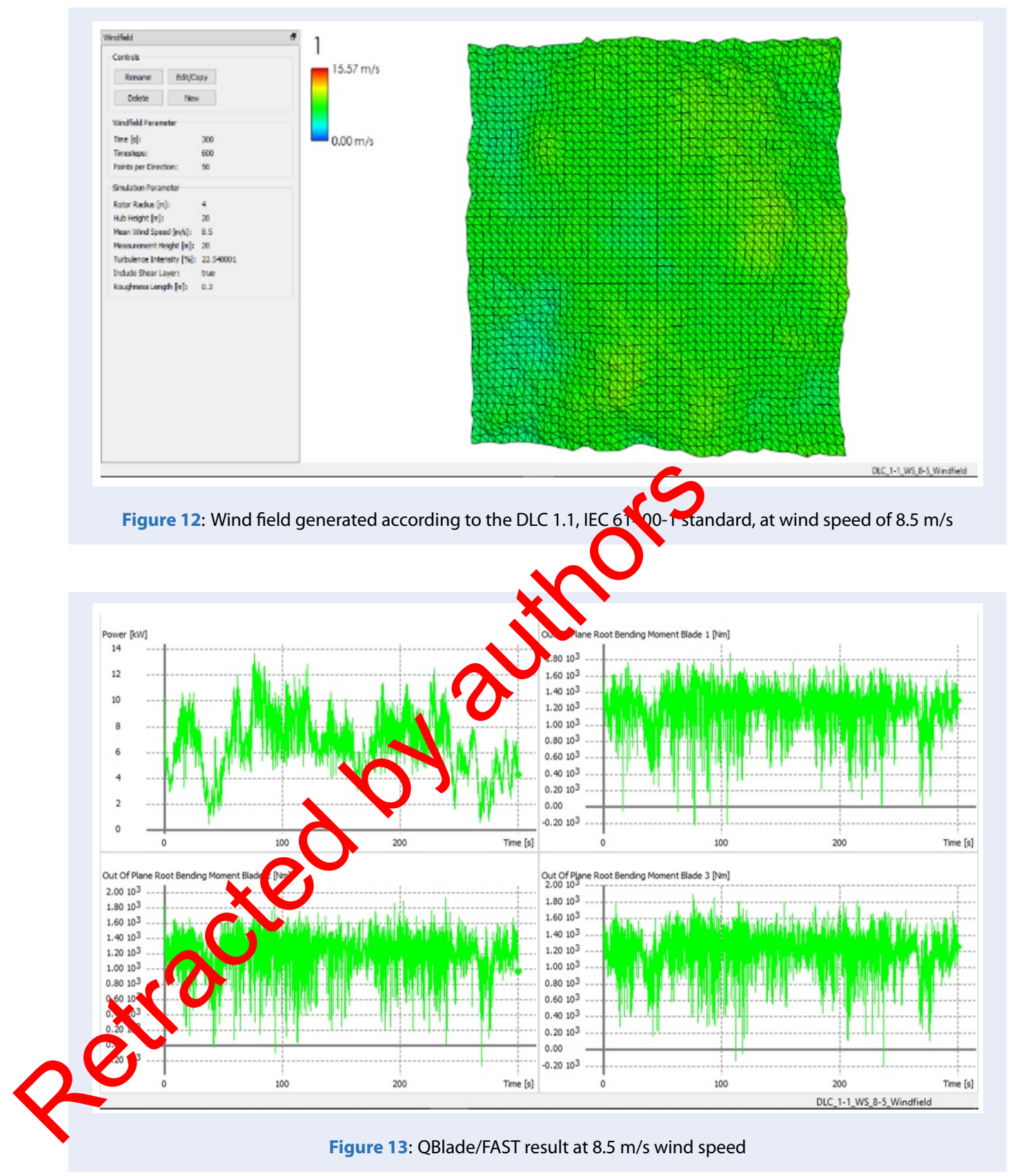

\section{Testing preparation of the blade}

The result of the blade's displacement and bending moment purpose is to determine the concentrated load in which to apply on the blade by the test rig. The goal of converting the distribution load to the according concentrated load is to make the bending moment curve to remain mostly the same, to make test possible since that is how the loads will be introduced to the blade by the test rig. Referred to the German expert knowledge, the suggested number of concentrating loads to be found are 4 , at the blade radius of 1 ,
2.2, 2.8, 3.4 meters respectively. Solving the system of equations resulted in the converted loads as shown in the Table 4, and the bending moment curve of two cases are shown in Figure 17.

\section{STATIC-LOAD TEST RIG}

\section{Main frame}

With the data provided by the blade analysis, the main frames are rigidly wielded at 4 chosen positions as shown in Figure 18 (blue frame), this give rigid mounting point for the load generating device and 


\section{Table 4: Distribution load converted to concentrating load}

\begin{tabular}{lll}
\hline Load position $(-)$ & Blade's radius $(\mathrm{m})$ & Force $(\mathrm{N})$ \\
1 & 1 & 1383.721 \\
2 & 2.2 & 1075.833 \\
3 & 2.8 & 36.110 \\
4 & 3.4 & 731.107 \\
\hline
\end{tabular}

structurally calculated to not contribute to the final displacement of the blade.

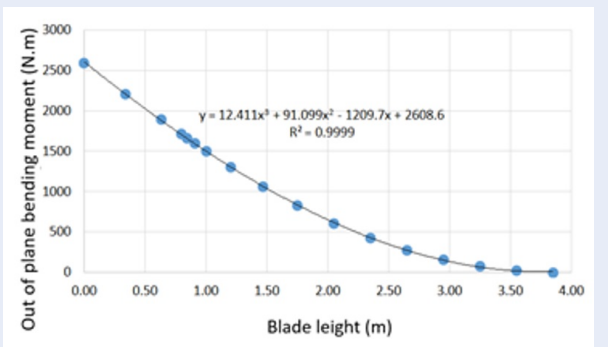

Figure 15: Out of plane bending moment at the respective blade length

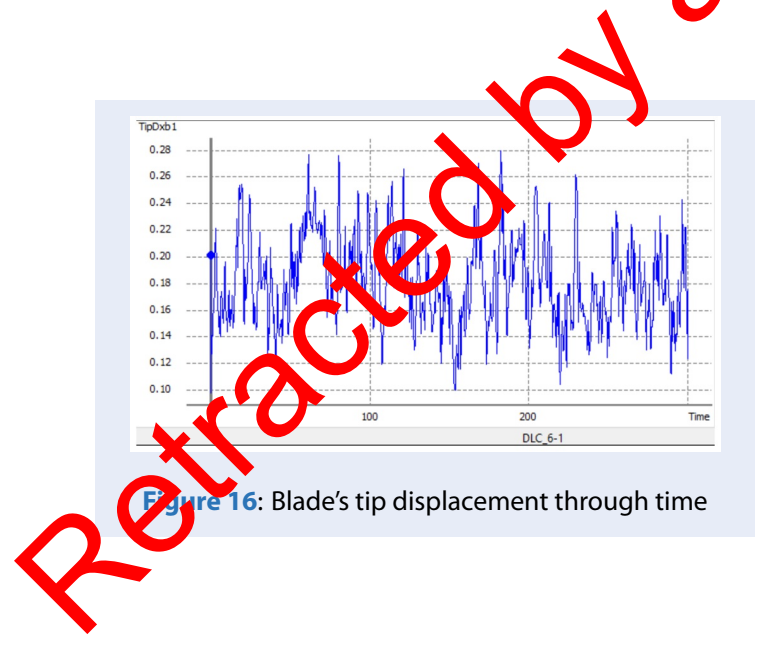

\section{Load generating concept and device}

For strong, safe and easy to control, the automatic car scissor jack ticked all the boxes. With its low cost hence easy replacement and modification. It also come with the nature of creating large amount of force with the worm gear pair mechanism, making it safe if the motor fails or following parts failed, the jack will not collapse, potentially damage the blade.

Figure 19 shown the load generating car jack in working position and how the force created transfer to the blade via a steel bar, connected to a cable and truckle system.

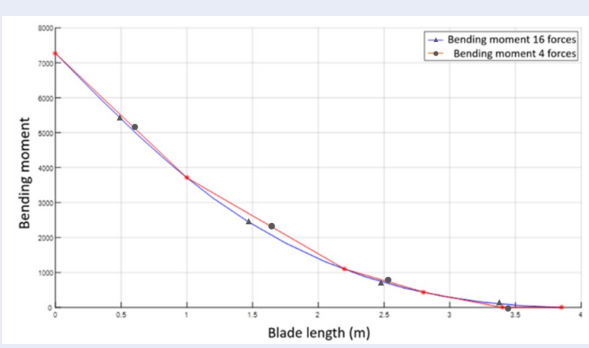

Figure 17: Bending moment from two loads cases

\section{Force sensor - Loadcell}

The Z-type loadcell chosen for having the best shape to fit between the blade and the steel cable that provide the load onto the blade. The signal cable come with its own shielded layer, connecting it to ground reduce the signal noise, which is necessary for good calibration and data logging.

Figure 20 and Figure 21 show the loadcell with the system used for calibration using a lab grade loadcell with higher capacity and accuracy, connecting in series and apply the same load on both, logging the data from both loadcell to find the conversion factor from 


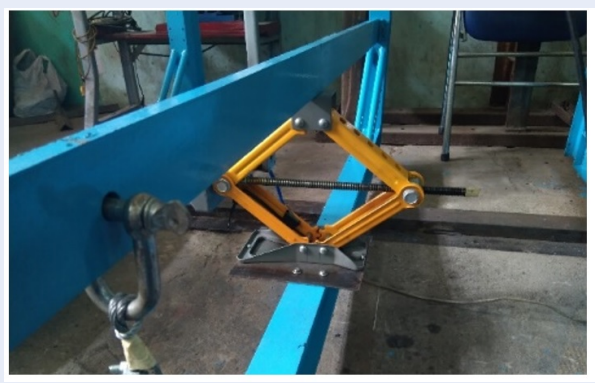

Figure 19: Load generating car jack in series with steel bar, cable and truckle

electricity signal to force unit of the calibrating loadcell. The loadcells after calibrating shown good result with only $1 \%$ error, repeated test also shown the result were consistent every time.

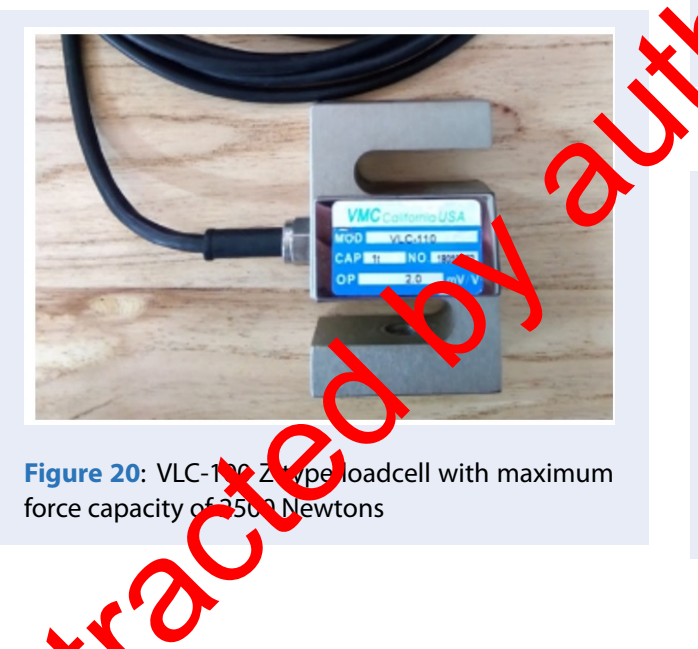

\section{Confroliting system}

Th A duino platform have been chosen to be the in processing unit. It come with the benefit of easy changing control algorithms hence fast prototyping. This platform ecosystem support for various modules of sensor and motor controlling drivers, making it more engaging in the try and error process of finding the best suited hardware. Figure 22 shown the final wiring diagram of the main processing unit to the 4 respectively loadcell as input and car jack as output. The car jack come standard with high speed DC motor, which is a disadvantage in this case since we want precise control of the loads generated. The DC motor have been replaced with a stepper motor, which is superior by enabling precise speed control, rotating direction and high torque at low rpm. All motor's parameters can be tweak via DIP switches on the motor drivers, and further refined in the controlling code.

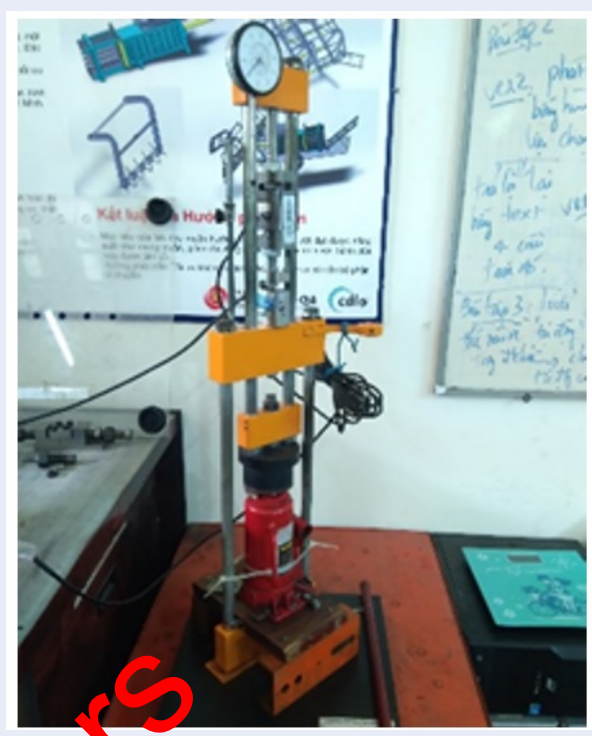

Fi ure 1: Connecting 2 loadcells in series for caliratun, the force come from a hydraulic jack capableof producing 10 tons of force

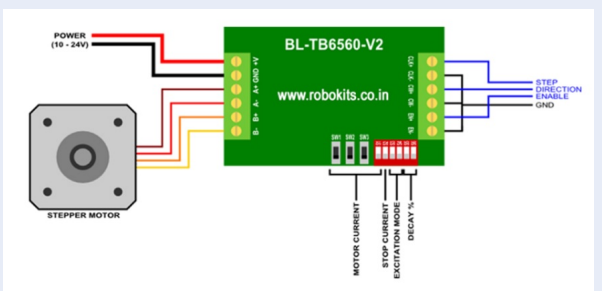

Figure 22: Stepper motor and driver wiring

Electronic wiring diagram of the loadcells and motor is shown in Figure 23.

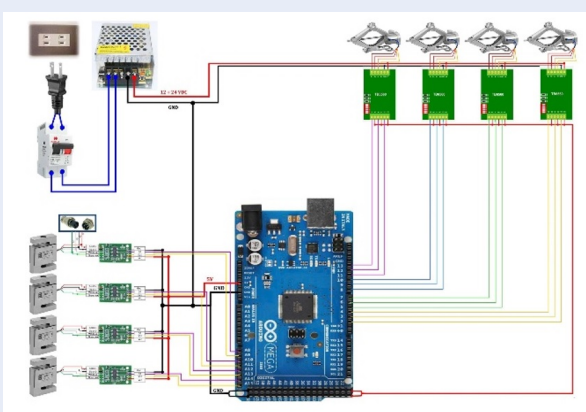

Figure 23: Electronic wiring diagram 


\section{Load frame}

As the test load only be applied to 4 sections of the blade, a load frame is needed and act as the load introduction point to the blade. Also protecting the blade of any localized deformation and maintain its internal structure integrity. The load frame was designed for each of the 4 selected air foils, with a gap for a softer material to accommodate (in this case a rubber flat strand), filling the variable air foil gap for better force transfer, and further cushioning, hence protects the blade outer layers and inner structure as shown in Figure 24.
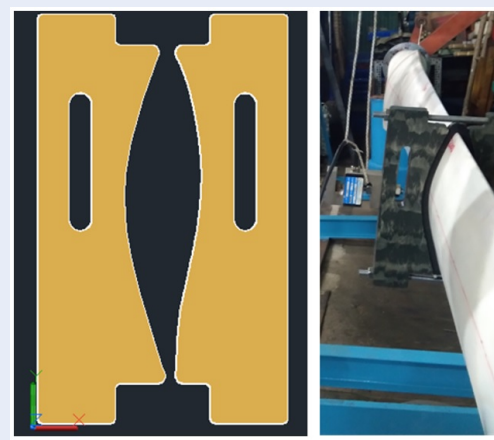

Figure 24: Load frame design and final ploduct attached on the blade, secured with-ong It connecting two parts, soft rubber fil $d$ in he ap between load frame and blad

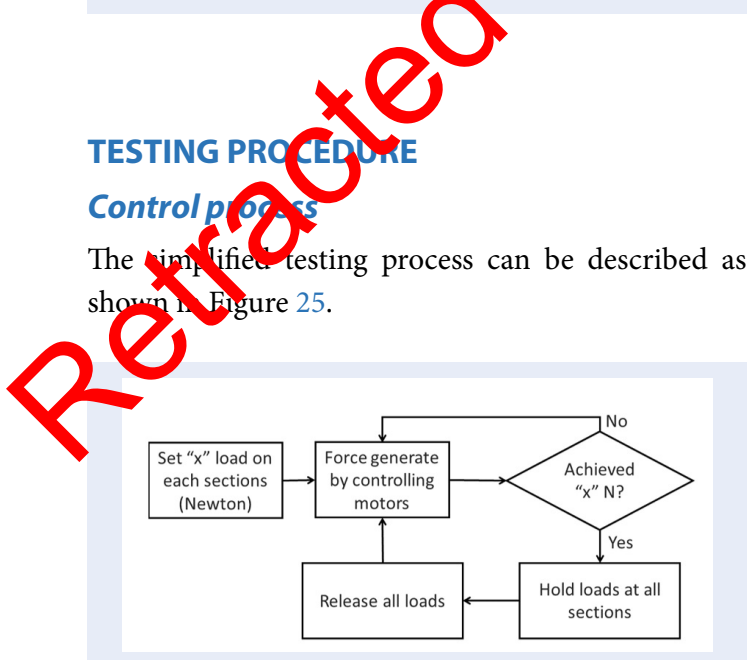

Figure 25: Testing process

The test will begin after putting in the forces parameter as shown in Table 4, including 4 different forces at the respective sections. The system has been integrated with several safety check to make sure the rig was ready to perform the test, also an emergency mode can be activated at any moment by the operator.
After passing all safety check, motors will start turning, generating force for each section. After reaching the desired force at all sections, the system holds for a set amount of time and release all forces gradually.

\section{Test result}

Figure 26 shown the tip displacement measured at 0.289 meters (the ruler starts at 0.1 meter). Figure 27 and Figure 28 shown the blade shape and tip position at rest and at full load. This result was consistent after many tests were conducted continuously.
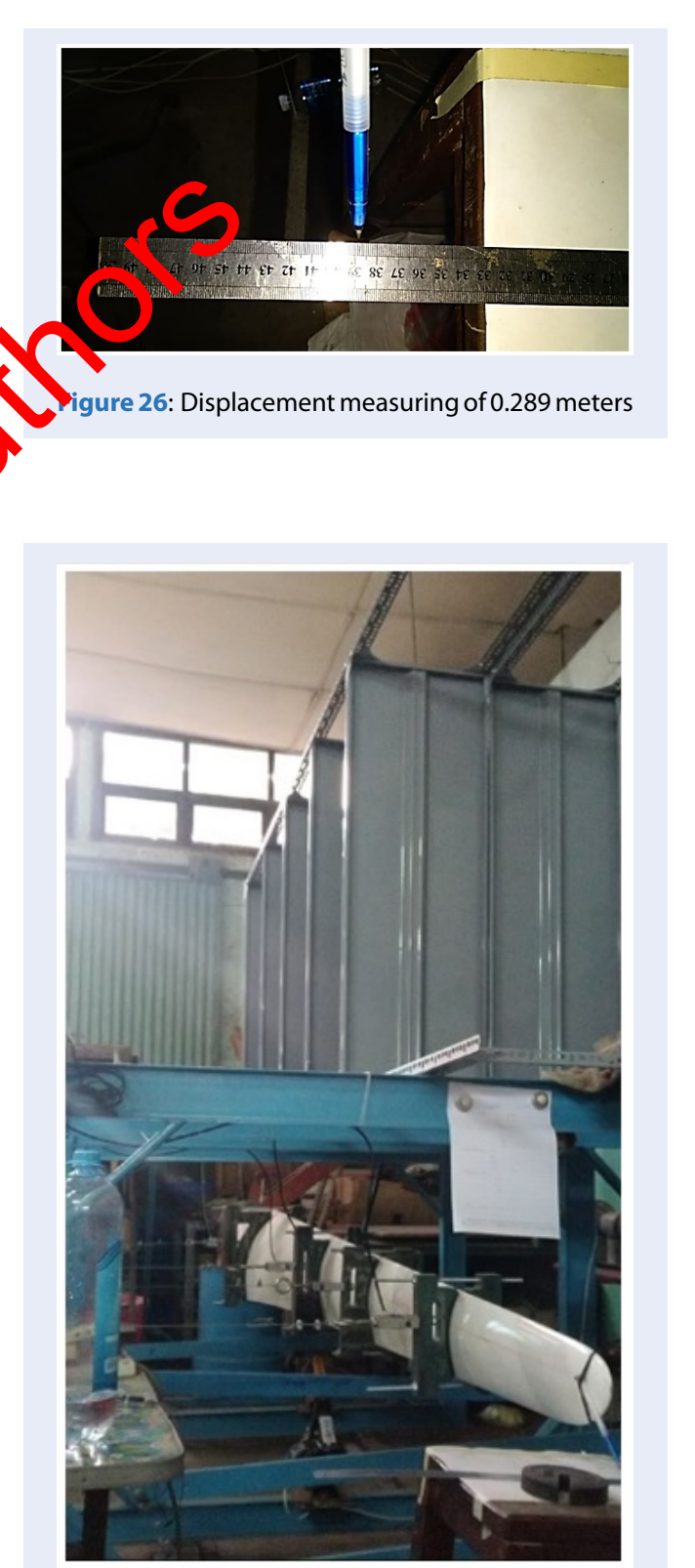

Figure 27: Blade at rest 


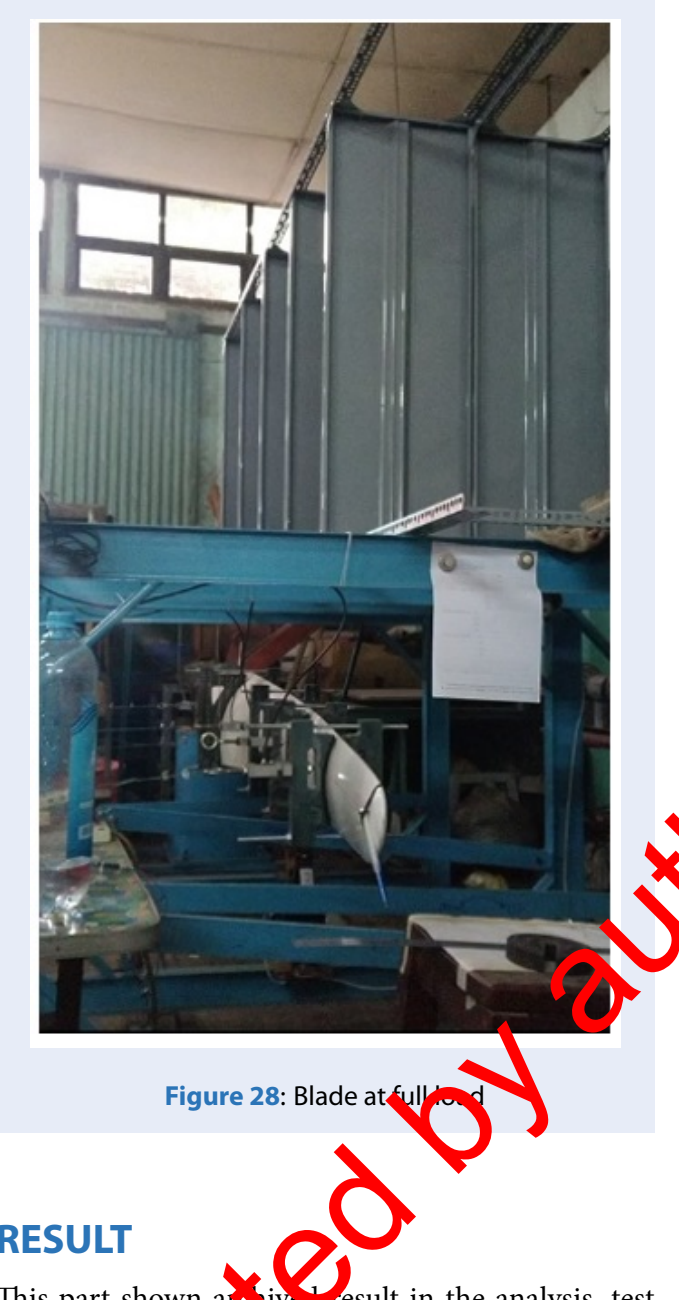

This part shown ara ivo esult in the analysis, test rig result, as $\mathrm{w} 1 \mathrm{las}$ discussion on the new points, main controu on and observations were made in the studx

Tip dis lasment result are widely used in the wind tu bie brade testing provider to give their customer a quative result on the design and manufacturing In this research, tip displacement result from the test rig was 0.289 meters, which closely match with the simulation result of 0.280 meters. The error does not exceed $5 \%$ between tests, this show the test rig was reliable and more importantly have high repeatability, which is essential targets of any test providers.

\section{DISCUSSION}

This paper works on a relatively new, interesting and practical subject of design a test rig for structural static load testing of small wind turbine blades with horizontal axis.

The results of the proposed test system were similar compared with the simulation results of the model blades subjected to the same operating conditions, this shown the analysis and selected parameter for the test rig from the IEC61400-23 standard and assumptions on the structure was correct. Also proved the important of knowhow knowledge from experts in combination with real life training experience will contribute in the success of the project.

\section{CONCLUSIONS}

As the green energy trend keep growing, Vietnam need a strong base of knowledge in this field in order to develop domestic wind turbine product. Contribute to the world efforts of reducing emission and moving to non-fossil fuel economy.

This project set the first step into the new field of testing wind turbine blade structure, this will streamline the process of design, manufacturing, testing, and employment of ate of the art Made in Vietnam wind turbine which mised to soon make it ways into the system

Fron thi basic but validated design of the test ig, ther improvement can be added in the future. Ex anding functionalities, safety features, produce quicker and more accurate result, helping the developer and manufacturer quickly integrate their design, reduce time to the market of the product.

\section{Future work}

This success once again shown the test system is ready for more function as the full structural blade test also need fatigue test, which exposed the blade to the high force cycle to simulate the 20 years of expected life span of the wind turbine. More adjustment needed for the static test, some of which are synchronizing the motors to achieve the same speed of force generation, behavior recognition algorithm to foreseen hazard and dangerous symptom of the system, as well as moving to more professional electrical hardware platform to increase the reliability and upgradability of the system in the long run.

\section{ACKNOWLEDGEMENT}

We sincerely thank the Engineering Mechanics Lab at HCMUT for great support on facility and tools to our research. This research is funded by HCMUT under grant number T-KHUD-2018-82. We acknowledge the support of time and facilities from Ho Chi Minh City University of Technology (HCMUT), VNU-HCM for this study.

\section{LIST OF ABBREVIATIONS USED}

- BEM: Blade Element Momentum

- DLC: Design load case

- HAWT: Horizontal Axis Wind Turbine 
- IEC: International Electrotechnical Commission

- QLLT: QBlade Lifting Line Theory

- R: Blade Radius

- RPM: Round per Minute

- TSR: Tip Speed Ratio

\section{AUTHORS' CONTRIBUTIONS}

All authors contributed equally to this work. All authors have read and agreed to the published version of the manuscript.

\section{COMPETING INTERESTS}

The author(s) declare that they have no competing interests.

\section{REFERENCES}

1. GIZ Energy Support Program, Overview of the Vietnamese Power Market - A Renewable Energy Perspective, Hanoi, Vietnam. 2015;

2. Nguyen DL. A Brief Overview on Assessments of Wind Energy Resource Potential in Vietnam. J. Fundam. Renewable Energy Appl. 2014;4:132.

3. Duncombe JU. Infrared navigation-Part I: An assessme to feasibility. IEEE Trans. Electron Devices. 1959;ED-1
4. International Electrotechnical Commission IEC 614001:2005+AMD1:2010: Wind turbines - Part 1: Design requirement. 2014;

5. Design of test rig for structural static-load testing of small horizontal axis wind turbine rotor blades, a research project funded by HCMUT from 12/2018 to 12/2019 (project number: T-KHUD-2018-82);

6. Son LH, Triet PM, Hieu NK. Ứng dụng phương pháp mô phỏng số để khảo sát ngược đặc tính của chân vịt lắp ngoài đi theo cưm máy Suzuki DF 9.9 HP. Tuyển tâp công trình hội nghị Cơ học toàn quốc lần X, Hà Nội. 2018;.

7. Hieu NK, Thien $P Q$, Nghia NH. Numerical analysis of LBV150 ROV thruster performance under open water test condition. Lecture notes in Electrical Engineering 465, Springer. 2018;Available from: https://doi.org/10.1007/978-3-319-69814-4_99.

8. Tang X. Aerodynamic Design and Analysis of Small Horizontal Axis Wind Turbine Blades. PhD. thesis report, University of Central Lancashire, Preston, UK. 2012;

9. Viterna LA, Corrigan RD. Fixed pitch rotor performance of large horizontal axis wind turbines. NASA Lewis Research Center, Cleve and, Ohio. NASA-CP-2230, NAS 1.55:2230, CONF810752 SL+1 CP 635-1273. 1982;

10. Sathish ymar IP, Satheeshkumar S, Jesuarockiam N. Glass , in urced polymer composites - A review. Journal of Reorce Plastics and Composites. 2014;33:1258-1275. Availle from: https://doi.org/10.1177/0731684414530790. Hieu NK, Khoi ND, Hung PQ. Khảo sát ngược đặc tính hoạt động của máy phát điện gió trục ngang với QBlade/FAST. Co hoc thủy khí toàn quốc lần thứ 22. 2019; 